\title{
ELECTROMYOGRAPHIC ACTIVITY OF VARIOUS MUSCLES DURING SIT-TO-STAND IN PATIENTS WITH STROKE: A META-ANALYSIS
}

\author{
Dimple Antiya ${ }^{1}$, Suvarna Ganvir ${ }^{2}$ \\ ${ }^{1}$ Post graduate student, ${ }^{2}$ Professor, Department of Neuro -Physiotherapy, \\ DVVPF's College of Physiotherapy, Ahmednagar, India.
}

\section{ABSTRACT}

Aims:-To provide a comprehensive information about analysis of activation of various muscles during Sit-to-Stand in patients with stroke. To determine if there exists any common pattern of muscle activation. To give direction to future studies regarding the muscles to be investigated during Sit-to-Stand. Methods- A literature search was performed with help of the most commonly used database i.e. PubMed to select the studies related to electromyographic activities of various lower extremity, trunk and upper extremity muscles during Sit-to-Stand activity, published till 2016. The Inclusion criteria for the study were Prospective or retrospective cohort studies, studies that included only participants with stroke leading to hemiparesis and/or along with healthy participants as control group and studies that measured the EMG activity in either trunk muscles and/or limb muscles during sit to stand. The exclusion criteria were if their population of interest also included patients with other neurological conditions and studies in any language other than English. Two independent investigators assessed the studies based on inclusion and exclusion criteria. Keywords used during the search were Electromyography, Stroke, Sit-to-Stand. The studies were thoroughly evaluated with respect to the Sit-to-Stand procedure and variety of muscles that were investigated through EMG analysis. Results: With the help of given keywords, abstracts/articles of 21 studies were retrieved from the database. After initial screening of the abstracts 12 studies were selected for in depth analysis. Various lower extremity muscles including Tibialis Anterior, Soleus, Quadriceps, Vastusmedialis, Gluteus Maximus were investigated in the studies. In 2 studies, Trunk muscles were investigated whereas in one study Triceps muscle activity was analyzed during Sit-to Stand activity in patients with stroke. Conclusion: From this study it can be concluded that the activity of Tibialis Anterior muscle was investigated more frequently by various researchers followed by the activity of Soleus and Quadriceps muscle.

KEYWORDS: Electromyography; Stroke; Sit-to-Stand.

\section{INTRODUCTION}

Stroke has an important impact on all components of functionality [1,2] and is considered one of the most common causes worldwide of long-term disability $[1,3]$. As pointed out by Riley et al. (4), rising from a chair and sitting down are two of the most mechanically demanding activities occurring in daily activities. Sitto-stand (STS) begins in a safe sitting position and progresses to an unstable standing position, and it requires the lower extremity and trunk muscles to work together in harmony [5].

Persons with stroke perform an inadequate STS and

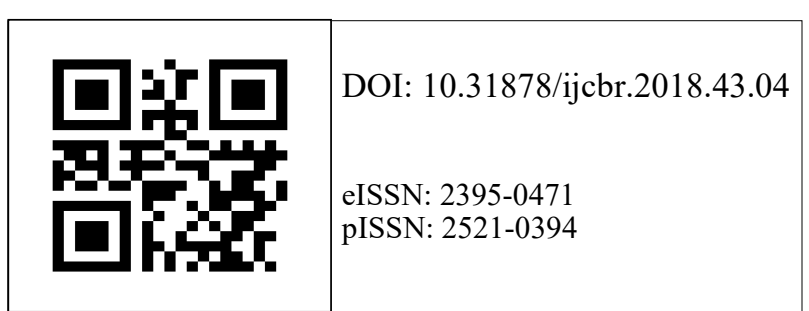

the majority of their weight is placed on the unaffected side, or the unaffected lower extremity is placed posterior to the affected lower extremity when they perform STS. This STS activity is analysed by various ways such as biomechanical analysis. Patients with neurological diseases, such as stroke, have difficulty performing the STS movement due to pain, spasticity, muscle weakness, sensory problems, and balance deficits in the affected limb [6,7]. In patients with stroke, the muscle recruitment patterns in the unaffected limb compensate for the muscle deficiencies of the affected or paretic limb. This compensatory pattern is often created to achieve balance [7].

At a certain stage, the quality of movement and the consequences of impairments observed during STS performance can be analyzed on the basis of the changes in lower limb muscle activation. However, trunk muscles also play an important role in STS [8]. Studies are conducted to investigate the certain

Correspondence: Dimple Antiya, Post Graduate student, Department of Neuro -Physiotherapy, DVVPF's College of Physiotherapy, Ahmednagar, India. Email: dimpleantiya@gmail.com 
Dimple et al. Electromyographic activity of various muscles during sit-to-stand in patients with stroke:

a meta-analysis.

lower extremity and trunk muscle group activation during STS including one study on triceps muscle $[9,10]$. These studies gives us a brief picture about pattern of muscle activation, also which muscle activity is seen prior to the other muscle during the activity. Also it does give quantitative information about different muscle's activation during the task. But, a comprehensive study investigating all lower extremity and trunk muscle activation is not done till date.

Hence the purpose of this systematic review is 1 . To provide comprehensive information about various muscles those are investigated through EMG analysis. 2. To determine if there exist any common pattern of muscle activation. 3 . To give direction to future studies regarding the muscles to be investigated for EMG analysis, during sit to stand (STS) activity.

\section{METERIALS AND METHODS}

Study design: Meta-analysis.

Study duration: A systematic literature search was conducted in July 2017.

Study place: DVVPF's College of Physiotherapy digital library.

Inclusion criteria: The Inclusion criteria were 1) Prospective or retrospective cohort studies, 2) studies that included only participants with stroke leading to hemiparesis and/or along with healthy participants as control group and 3) studies that measured the EMG activity in either trunk muscles and/or limb muscles during sit to stand.

Exclusion criteria: The exclusion criteria were if their population of interest also included patients with other neurological conditions and studies in any language other than English.

Sample size: The total number of records identified by the search of PubMed were 21. After deep analysis, 9 were excluded due to incomplete and missing inclusion criteria details. Therefore, 12 studies were included in the review.

All studies related to EMG studies during the sit to stand activity in patients with stroke were sought. To achieve this, through the most commonly used search engine Pubmed. A combination of the following keywords and MeSH terms were used: EMG, Stroke, Sit to Stand.

Study selection and data extraction.

To begin with, two reviewers (Dimple Antiya, Suvarna Ganvir) independently read the titles and/or abstracts of the identified studies with respect to the inclusion and exclusion criteria. Irrelevant studies were removed from the list. Potentially eligible studies were read fully by both reviewers and their suitability for inclusion was independently determined by both of them. Disagreement was resolved by consensus.

Data Extraction: Preliminary information was extracted from the each eligible study which included: study type and setting, patient demographics (age, gender) and clinical characteristics including relevant inclusion and exclusion criteria, muscles studied for EMG activity, and the task given to the participants was noted. In case of a query about the study, authors were contacted by email for clarification. Each study was read in details by both authors separately. Record was derived for commonly tested muscles with the help of EMG, the extent of affection, clinical application of results.

Flow of the studies through the review: the total number of records identified by the search of PubMed were 21. After initial screening of titles and abstracts, 3 studies were excluded ( 2 because - EMG analysis was not done, 1 because - patients with Parkinsonism were included). After full text review, of the remaining 18 studies, 6 studies were excluded because they were experimental studies and baseline values were not provided clearly. Therefore, 12 studies were included in the review. This is shown in Table 1.

Characteristics of the participants included in the studies: Out of 12 studies, 8 studies were done exclusively on patients with stroke. In the remaining 4 studies, along with patients with stroke, healthy control participants were also included. Total 220 patients with stroke and 85 volunteers were included in studies. The mean age of patients varied from 52 years to 71 years. The mean duration of stoke varied from 2 months to 24 months. The majority of patients were with right side hemiparesis. Details are given in Table 1.

Details of the EMG analysis: Different muscle groups were analyzed with the help of EMG in different articles. It varies from ankle muscles in the form of Tibialis Anterior, Soleus to Knee joint muscles such as quadriceps and hamstrings. In certain studies, Hip joint muscle viz Gluteus Maximus and trunk muscles viz Abdominals and back extensor muscles were included. Table 1 gives the summary of this analysis.

Sit to Stand Activity: There was a moderate variation in the procedure of sit to stand activity across the studies included. This variation is in a form of height of a couch, adjustable seat height use of a arm rest, back rest and leg brace, use of a cane and position of legs with respect to each other and degree of flexion of knee joint. This variation may also lead to differences in activation patterns of different muscles during the task of STS. 
Dimple et al. Electromyographic activity of various muscles during sit-to-stand in patients with stroke:

a meta-analysis.

Table 1. Brief description of this activity.

\begin{tabular}{|c|c|c|c|}
\hline Author & Participants & Muscles for EMG & Sit to stand activity \\
\hline $\begin{array}{l}\text { Rie Kasai, Sunao } \\
\text { Takeda [11] }\end{array}$ & $\begin{array}{l}5 \text { patients } \\
\text { with stroke }\end{array}$ & Vastusmedialis & $\begin{array}{l}\text { Rehabilitation couch } 45 \mathrm{~cm} \text { high, use of a leg } \\
\text { brace and arm support were allowed }\end{array}$ \\
\hline $\begin{array}{c}\text { Tae-Heon Lee, } \\
\text { Jong-Duk } \\
\text { Choi, Nam-Gi Lee } \\
\text { [12] }\end{array}$ & $\begin{array}{l}20 \text { adults } \\
\text { with chronic } \\
\text { stroke }\end{array}$ & $\begin{array}{l}\text { Transverse } \\
\text { abdominis/internal } \\
\text { oblique, rectus femo- } \\
\text { ris, tibialis anterior }\end{array}$ & $\begin{array}{l}\text { Chair seat was adjusted to the height of their knee } \\
\text { joints. STS movement was performed barefoot, } \\
\text { and the distance between each foot was 10-15 } \\
\text { cm depending on body size. The STS movement } \\
\text { began with a straight trunk, } 10 \text { degrees of ankle } \\
\text { dorsiflexion, and 100-105 degrees of knee flexion } \\
\text { measured using a goniometer. }\end{array}$ \\
\hline $\begin{array}{l}\text { Inkyeong Nam, Jin } \\
\text { Shin Yoseb Lee, } \\
\text { Mi Young Lee, } \\
\text { Yijung Chung [9] }\end{array}$ & $\begin{array}{l}15 \text { patients } \\
\text { with stroke }\end{array}$ & $\begin{array}{c}\text { Erector spinae and } \\
\text { gluteus maximums } \\
\text { muscles }\end{array}$ & $\begin{array}{l}\text { STS using three different strategies: symmetric } \\
\text { foot position, unaffected foot placed behind the } \\
\text { affected foot position (asymmetric-1), and affect- } \\
\text { ed foot placed behind the unaffected foot position } \\
\text { (asymmetric-2). }\end{array}$ \\
\hline $\begin{array}{l}\text { Judith M. } \\
\text { Burnfield, Berna- } \\
\text { dette McCrory, } \\
\text { Yu Shu, Thad [13] }\end{array}$ & $\begin{array}{l}10 \text { patients } \\
\text { with stroke }\end{array}$ & $\begin{array}{l}\text { Vastus Medialis, } \\
\text { gastrocnemius, solu- } \\
\text { eus, hamstrings, } \\
\text { vastuslateralis }\end{array}$ & $\begin{array}{l}\text { 45.7cm high (18-in-high), armless, and backless } \\
\text { Chair }\end{array}$ \\
\hline $\begin{array}{c}\text { Hu PT, Lin KH, Lu } \\
\text { TW, Tang PF, Hu } \\
\text { MH, Lai JS.[14] }\end{array}$ & $\begin{array}{l}9 \text { patients } \\
\text { with stroke }\end{array}$ & Knee extensor & $\begin{array}{l}\text { Height-adjustable, armless, and backless chair, } \\
\text { with bare feet placed on two separate force } \\
\text { plates in front of the chair, with knee flexion. } \\
\text { At about } 105 \text { degrees, ankle dorsiflexion at } 15 \\
\text { degrees, and intermalleoli distance of about } 15 \\
\mathrm{~cm} \text {. }\end{array}$ \\
\hline $\begin{array}{l}\text { Prudente C, Ro- } \\
\text { drigues-de- } \\
\text { Paula F, Faria [8] }\end{array}$ & $\begin{array}{l}10 \text { patients } \\
\text { with stroke. }\end{array}$ & $\begin{array}{l}\text { Tibialis anterior, } \\
\text { soleus, quadriceps }\end{array}$ & $\begin{array}{l}\text { The seat was adjusted to } 100 \% \text { of the height of } \\
\text { the subjects' knees, determined by the distance } \\
\text { between the knee joint line and the floor. The } \\
\text { subjects were instructed to stand as fast as they } \\
\text { saw the visual signal given by the monitor and to } \\
\text { remain standing until the end of the record. } \\
\text { They were required to fold their arms across } \\
\text { the chest to prevent the use of the upper limbs }\end{array}$ \\
\hline $\begin{array}{l}\text { Augusta Silva et al } \\
{[15]}\end{array}$ & $\begin{array}{l}10 \text { subjects } \\
\text { with stroke and } \\
10 \text { healthy volun- } \\
\text { teers }\end{array}$ & $\begin{array}{l}\text { Soleus and } \\
\text { Tibialis anterior }\end{array}$ & $\begin{array}{l}\text { Chair modified to the height of his knee and } \\
\text { without armrests and backrests. The feet were } \\
\text { placed in parallel to each other with the heels } 10 \\
-15 \mathrm{~cm} \text { apart. Each participant's ankle was posi- } \\
\text { tioned at approximately } 10 \text { degrees of dorsiflex- } \\
\text { ion, and the knee angle was } 100-105 \text { degrees of } \\
\text { flexion. }\end{array}$ \\
\hline $\begin{array}{l}\text { Ana Cristina R. Ca- } \\
\text { margos, Fátima } \\
\text { Rodrigues-de-Paula- } \\
\text { Goulart [16], }\end{array}$ & $\begin{array}{l}20 \text { chronic } \\
\text { stroke }\end{array}$ & $\begin{array}{c}\text { Tibialis Anterior, } \\
\text { Soleus, Quadriceps } \\
\text { and Hamstrings }\end{array}$ & $\begin{array}{l}\text { Subjects' feet supported on the Balance Master } \\
\text { System platform and their arms across the chest } \\
\text { to prevent the use of the upper limbs during the } \\
\text { execution of the task. The participants were } \\
\text { instructed not to move their feet and to stand } \\
\text { as fast as possible from the initial instructions of } \\
\text { the Balance Master System. When the standing } \\
\text { position was attained, they were asked to main- } \\
\text { tain this position for } 5 \text { seconds. }\end{array}$ \\
\hline
\end{tabular}




\begin{tabular}{|c|c|c|c|}
\hline $\begin{array}{c}\text { Pao-Tsai Cheng, } \\
\text { Chia-Ling Chen, } \\
\text { Chin-Man Wang, } \\
\text { Wei-Hsien Hong, } \\
\text { MS [17] }\end{array}$ & $\begin{array}{l}40 \text { non fallers, } \\
20 \text { fallers Hemi- } \\
\text { plegic patients } \\
\text { with stroke. } \\
20 \text { healthy vol- } \\
\text { unteers }\end{array}$ & $\begin{array}{c}\text { Tibialis anterior } \\
\text { and soleus }\end{array}$ & $\begin{array}{l}\text { Armless, backless chair that was adjusted to the } \\
\text { height of the subject's knee (determined as } \\
\text { the distance from the lateral knee joint line to } \\
\text { the floor). The feet were placed in parallel, one } \\
\text { foot on each force plate, with the medial bor- } \\
\text { ders of the feet } 10-15 \mathrm{~cm} \text { apart, determined ac- } \\
\text { cording to the subject's body size. Each subject's } \\
\text { ankle was placed at approximately } 10 \text { degrees of } \\
\text { dorsiflexion and the knee angle was at } 100-105 \\
\text { degrees of flexion. }\end{array}$ \\
\hline $\begin{array}{c}\text { Denis Brunt,Brigid } \\
\text { Greenberg, Sharmin } \\
\text { Wanka dia, MHS, } \\
\text { Mark A. Trimble, } \\
\text { Orit Shechtman } \\
\text { [18], }\end{array}$ & $\begin{array}{c}10 \text { patients } \\
\text { with stroke and } \\
10 \text { healthy volun- } \\
\text { teers }\end{array}$ & $\begin{array}{l}\text { Tibialis anterior } \\
\text { and quadriceps }\end{array}$ & $\begin{array}{l}\text { For testing, subject were barefoot, dressed in } \\
\text { shorts, and seated on a height- adjustable bench } \\
\text { with their thighs unsupported. The bench was } \\
\text { adjusted to the height of the subject's Knee } \\
\text { (determined as the distance from the joint line to } \\
\text { the floor). The bench was aligned just behind } \\
\text { the posterior edge of the force plates. The sub- } \\
\text { ject's feet were placed in parallel, one on each } \\
\text { force plate. Marks on each thigh a n d a r o u n d } \\
\text { the subject's heels were made to reference their } \\
\text { position on the bench and the force plates for } \\
\text { consistency between trials. Subjects were re- } \\
\text { quired to fold their arms across their chest, keep- } \\
\text { ing their palms flat against their rib cage to pre- } \\
\text { clude the use of their hands. }\end{array}$ \\
\hline $\begin{array}{c}\text { Lee MY, Wong MK, } \\
\text { Tang FT, Cheng PT, } \\
\text { Chiou WK \& Lin PS } \\
{[10]}\end{array}$ & $\begin{array}{c}14 \text { patients } \\
\text { with stroke and } \\
9 \text { healthy } \\
\text { volunteers }\end{array}$ & $\begin{array}{c}\text { Quadriceps, } \\
\text { Hamstrings, Tibialis } \\
\text { anterior, and triceps } \\
\text { surae }\end{array}$ & $\begin{array}{l}\text { Armless, backless chair which was adjusted until } \\
\text { their thighs were approximately parallel to the } \\
\text { floor. The feet were placed parallel, } 20 \mathrm{~cm} \text { apart } \\
\text { and flat on the floor. The chair was positioned } \\
\text { such that only the subjects feet were both on } \\
\text { the force platform. The initial knee angle was } \\
\text { set at } 110 \text { degree of flexion }\end{array}$ \\
\hline Rong Rong LU [19] & $\begin{array}{l}32 \text { patients with } \\
\text { stroke and } \\
\text { 36healthy volun- } \\
\text { teers }\end{array}$ & $\begin{array}{l}\text { Quadriceps, Ham- } \\
\text { strings, Tlbialis Ante- } \\
\text { rior, Gastrocnemius }\end{array}$ & $\begin{array}{l}\text { Armless, backless chair which was adjusted until } \\
\text { their thighs were approximately parallel to the } \\
\text { floor. } 50 \mathrm{~cm} \text { chair height was used. Initially ankle } \\
\text { were placed approximately at } 10 \text { degrees of dor- } \\
\text { siflexion and knee angle was set at 100-105 de- } \\
\text { grees of flexion. }\end{array}$ \\
\hline
\end{tabular}

Muscle activity was analyzed in terms of Root mean square values, Maximal amplitude, Average amplitude, Peak amplitude. This was compared with either non affected side muscles or with muscles of healthy volunteers. From the detailed analysis of the results of these studies it was found that the affected side muscles showed increased activity suggesting more effort being done by these muscles in order to accomplish the activity. Muscle activation patterns were also investigated. Majority of the study findings indicate that Tibialis anterior muscle got activated earlier than other muscles suggesting its clinical application in those patients who finds difficulty in standing up.

\section{DISCUSSION}

From the available studies it is quite evident that, electromyographic activity of Tibialis anterior and soleus is analyzed by more number of investigators. Other muscles studied were Quadriceps, Hamstrings, Gastrocnemius, Vastus Medialis and Gluteus Maximus. Trunk muscle activity was analyzed in only two studies and only one study has included activity of upper extremity muscle (triceps). So it is very clear that there is no single study which has analyzed all muscles of lower extremity along with or without trunk muscle activity analysis. Nevertheless these studies provide a preliminary idea about different muscle activation during STS in patients with stroke.

Characteristics of EMG analysis :Onset time of activi- 
Dimple et al. Electromyographic activity of various muscles during sit-to-stand in patients with stroke:

a meta-analysis.

Table 2. Description of muscle activity along with results obtained in the included studies.

Author : Rong Rong LU (2016):

Muscles for EMG: Quadriceps, Hamstrings, TIbialis Anterior, Gastrocnemius

Comparison group: Sit to stand

Result: ANOVA, Mann Whitney test was used for analysis. Area under curve for the non-paretic side was more for Quads, Hams, TA and Gastro i.e.74.92 $\pm 103.60,945.61 \pm 1652.21,405.92 \pm 659.84$ and $263.48 \pm 645.23$ than the paretic side for Quads, Hams, TA and Gastro i.e 61.26 $\pm 46.47,81.35 \pm 99.16,239.52 \pm 319.65$ and $39.08 \pm 41.97$ respectively.

During STS muscle utilisation of both the side increased and MUR of the paretic side is similar to the nonparetic side.

Author: Rie Kasai, Sunao Takeda (2016)

Muscles for EMG: Vastus medialis

Comparison group: With and without HAL(hybrid assisted limb)

Result: Average IEMG activity for STS was 83.6 whereas for Standing it was 6.3. Hence, reduced IEMG activity in vastus medialis in standing with support was seen.

Author: Tae-Heon Lee, Jong-Duk Choi, Nam-Gi Lee (2015)

Muscles for EMG: Transverse abdominis/internal oblique, rectus femoris, tibialis anterior

Comparison group: Unaffected side

Result: One way ANOVA, Bonferroni post hoc test were used for statistical analysis.

During the STS movement, there were significant differences in the EMG reaction time between the affected and unaffected sides in individuals with chronic hemiparetic stroke.(root mean square EMG amplitude for $\operatorname{TrA} / \mathrm{RF}$ and TA was $1.16 \pm 0.29,1.30 \pm 0.14 \& 1.05 \pm 0.25$ respectively for the Affected side and $0.99 \pm 0.31,1.11 \pm 0.29 \& 0.81 \pm$ 0.22 respectively for the unaffected side). According to the Bonferroni post hoc test, there were also significant differences in the EMG reaction time between the TrA/IO and TA muscles $(p=0.024)$ and the RF and TA muscles ( $p$ $=0.000)$, although not between the TrA/IO and RF muscles $(p=0.067)$.EMG reaction time of the TrA/IO muscles was delayed relative to that of the RF and TA

Authors: Inkyeong Nam, Jin Shin Yoseb Lee, Mi Young Lee, Yijung Chung (2015)

Muscles for EMG: Erector spinae and gluteus maximums muscles

Comparison group: Unaffected side

Asymmetric 1- affectedfootinfront

Asymmetric 2-affected foot behind

Result: One-way repeated measure ANOVA was used as statistical test. The unaffected erector spinae muscle activation was significantly greater $(173.5 \pm 83)$ when the affected foot was placed behind the unaffected foot (asymmetric-2) than when the unaffected foot was placed behind the affected foot(151.2 \pm 76.5$)$

Authors: Judith M. Burnfield, Bernadette McCrory, Yu Shu, Thad (2013)

Muscles for EMG: Vastus medialis, gastrocnemius, solueus, hamstrings, vastus lateralis

Comparison group: clinician-assisted, device assisted with no patient effort, device-assisted with the patient's best effort, and device- and clinician-assisted.

Result: one-way repeated measure ANOVA was used for statistical analysis. Device assisted transfers took nearly twice as long as clinician-assisted transfers. Hip and knee joint movement patterns were similar across all conditions. Forward trunk flexion was lacking and ankle motion was restrained during device assisted transfers.

Authors: Hu PT, Lin KH, Lu TW, Tang PF, Hu MH, Lai J-S. (2013)

Muscles for EMG: Knee extensor

Comparison group: Sit to stand

Result: Paired t test and independent t test was used for statistical analysis. The movement time of the subjects with hemiparesis in both conditions without a cane and with a cane was longer than that of the healthy subjects without a cane (P G 0.025). However, STS transfer with a cane in the subjects with hemiparesis resulted in shorter movement time, greater knee extensor moment of the paretic limb, and more symmetry of weight bearing than in those without a cane (P G 0.05). The sequence of muscle onset tended to improve with a cane in the subjects with hemiparesis. Cane use may promote more symmetrical STS transfers rather than compensation by the unaffected limb 
ty - In a study conducted by Tae-Heon Lee [12] Tibialis Anterior got activated prior to other muscles which may a mechanism to facilitatethe STS movement by compensating for the delayed activation of the TrA/ IO muscles. However, A study conducted by Inkyeong Nam [9] concluded that the activity of Erector Spinae was lesser on affected side whereas activity of GM was greater on affected side. Effect of cane was observed by Hu P-T [14] in his study. He concluded that there was no significant difference in the onset time of the major lower extremity muscles in both legs of the subjects with hemiparesis between STS transfer with a cane and without a cane. He further states that TA was activated early in affected side extremity as compared to unaffected side but it was not statistically significant. Since the affected side muscles gets activated early, they may get fatigued earlier and hence could result in poor sustenance during the activity.

Ana Cristina $\boldsymbol{R}$ [16]. Compared the muscle activities in three different positions of foot viz symmetrical foot position, asymmetrical foot position with affected foot in front, unaffected foot infront. It was observed that the beginning of the SOL muscle activation was delayed when the unaffected foot was placed behind, in comparison to the spontaneous strategy. However, the differential latencies of the SOL muscle showed that this muscle was activated before the seat- off during all investigated strategies. Hamstring was less activated in the symmetric strategy. No differences in the differential latencies of the TA, QUAD, and hamstring muscles were found between the strategies, and these muscles were also activated before the initiation of the seat-off and the same behaviors were observed with healthy subjects. However, a study conducted by Pao Tsai Cheng found contradictory result in the form of the mean onset time of TA activities was significantly delayed in the affected limbs of patients with stroke, especially in stroke fallers. TA activation first, followed by QUA, then HAM, and then SOL activation. So the common pattern observed was Tibialis anterior getting activated prior to other muscles of lower extremity. This information may be useful for clinical training of sit to stand activity.

Strength of muscle activity - Denis Brunt [16] studied the effect of 3 different conditions: (1) normal condition, where both limbs were placed in $100^{\circ}$ of knee flexion; (2) limb extended condition, where the dominant or uninvolved limb was extended to $75^{\circ}$ of knee flexion; and (3) limb elevated condition, where the dominant or uninvolved limb was placed on a dense foam support equal to $25 \%$ of the subject's knee height, in patients with stroke and healthy volunteers. Tibialis Anterior and Quadriceps muscle activity was studied with the help of EMG. They found that there was an increase in Tibialis Anterior activity of the involved limb. This increase was $29 \%$ for the legextended condition and $51 \%$ for the limb-elevated con- dition compared with the normal trials. A study by Rong Rong Lu [19] on muscle activity of Quadriceps and Hamstring Tibialis anterior and Gastrocnemius during sit to stand in patients with stroke and healthy volunteers. No significant difference in Average Amplitude (AA) and Maximum Amplitude (MA) of Quadriceps on non-paretic side of patients and that of healthy participants. $A A$ and $M A$ on paretic side was significantly lower than that of healthy individuals. HAMS- AA and Area Under Curve (AUC) of paretic side were statistically less than that of non-paretic side. TA- All parameters were significantly lower on paretic side as compared to non-paretic side. GAS- AA and MA on paretic side were significantly less than that of non-paretic side. AUC on paretic side was significantly greater than that of healthy participants. Muscle Utilization ratio, which is the relationship between muscle contraction moment and muscle contraction, was found to be more in patients with stroke as compared to healthy volunteers. As expected, the strength of contraction measured in terms of Root mean Square on affected side was less as compared to unaffected side. However, no comparison of strength of contraction can be made among the various muscle groups on the affected side only due to the lack of a single study involving same sample of patients.

Future research: There is a lack of a single study which has investigated all the muscles of lower extremity on a single group of patients and such study can be taken up in future. Also, the concept of Muscle Utilization ratio, which is relationship between muscle contraction moment and muscle contraction, can be studied for various muscles involved in the task of sit to stand.

\section{CONCLUSION}

From the study it can be concluded that activity of Tibialis Anterior (TA) muscle is investigated more frequently by various researchers, followed by activity of Soleus and Quadriceps muscle. Common pattern observed during sit to stand activity is that the Tibialis anterior muscle gets activated earlier than other muscles. However a there is no single study wherein all muscles' activity is analysed during sit to stand in patients with stroke.

\section{REFERENCES}

1. Geyh S, Cieza A, Schouten J, Dickson H, Frommelt P, Omar Z, et al. ICF Core Sets for stroke. J Rehabil Med. 2004; 44(S):135-41.

2. Duncan P. Stroke disability. Phys Ther. 1994;74 (5):399-407.

3. Murray CJL, Lopez AD. Global mortality, disability, and the contribution of risk factors: Global burden of disease study. Lancet. 1997;349 (9063):1436-42. 
Dimple et al. Electromyographic activity of various muscles during sit-to-stand in patients with stroke:

a meta-analysis.

4. Riley $P$, Shcenkman M, Mann R, Hodge W. Mechanics of a constrained chair-rise. J Biomech. 1991;24(1):77-85.

5. Yu B, Holly-Crichlow N, Brichta P, Reeves GR, Zablotny CM, Nawoczenski DA. The effects of the lower extremity joint motions on the total body motion in sit-to-stand movement. Clin Biomech. 2000;15(6):449-55.

6. Aruin AS, Hanke T, Chaudhuri G. Compelled weight bearing in persons with hemiparesis following stroke: the effect of a lift insert and goal directed balance exercise. J Rehabil Res Dev, 2000;37: 65-72.

7. Eng JJ, Chu KS. Reliability and comparison of weight-bearing ability during standing tasks for individuals with chronic stroke. Arch Phys Med Rehabil, 2002, 83: 1138-1144

8. Prudente C, Rodrigues-de-Paula F, Faria CDCM: Lower limb muscle activation during the sit-tostand task in subjects who have had a stroke. Am J Phys Med Rehabil 2013;92:666675.

9. Inkyeong Nam, Jin Shi, Yoseb Lee, Mi Young Lee, Yijung Chung The effect of foot position on erector spinae and gluteus maximus muscle activation during sit-to stand performed by chronic stroke patients J. Phys. Ther. Sci. 27: 571-573, 2015

10. Lee MY, Wong MK, Tang FT, Cheng PT, Chiou WK, Lin PS. New quantitative and qualitative measures on functional mobility prediction for stroke patients, Journal of Medical Engineering \& Technology. 1998;22:1, 14-24,

11. Rie Kasai, Sunao Takeda. The effect of a hybrid assistive limb on sit- to-stand and standing patterns of stroke patients J. Phys. Ther. Sci. 2016:1786-1790,

12. Tae-Heon Lee, Jong-Duk Choi, Nam-Gi Lee Activation timing patterns of the abdominal and leg muscles during the sit-to-stand movement in individuals with chronic hemiparetic stroke. J. Phys. Ther. Sci. 2015;27: 3593-3595

13. Burnfield JM, McCrory B, Shu Y: et al. Compara- tive kinematic and electromyographic assessment of clinician- and device-assisted sitto-stand transfers in patients with stroke. Phys Ther. 2013;93:1331-1341

14. Hu PT, Lin KH, Lu TW, Tang PF, Hu MH, Lai JS. Effect of a cane on sit-to-stand transfer in subjects with hemiparesis; Am J Phys Med Rehabil 2013;92:191Y202.

15. Augusta Silva, Andreia S. P. Sousa, Rita Pinheiro, Joana Ferraz, Joa o Manuel R. S. Tavares, Rubim Santos, Filipa Sousa: Activation timing of soleus and tibialis anterio muscles during sitto-stand and stand-to-sit in post-stroke vs. Healthy subjects. Somatosensory and Motor Research.2013; 30(1): 48-55

16. Camargos AC, Rodrigues-de-Paula-Goulart F, Teixeira-Salmela LF: The effects of foot position on the performanceof the sit-to-stand movement with chronic stroke subjects; Arch Phys Med Rehabil 2009;90:314-9.

17. Cheng PT, Chen $\mathrm{CL}$, Wang $\mathrm{CM}$, Hong WH: Leg muscle activation patterns of sit-to- stand movement in stroke patient. Am J Phys Med Rehabil. 2004;83:10-16.

18. Brunt D, Greenberg B, Wankadia S, Trimble $M A$, Shechtman $O$. The effect of foot placement on sit to stand in healthy young subjects and patients with hemiplegia. Arch Phys Med Rehabil. 2002;83:924-9.

19. Rong R. LU, Fang L, Bing ZHU. Electromyographical characteristics and muscle utilization in hemiplegic patients during sit-to-stand activity: an observational study. European Journal of Physical and Rehabilitation Medicine. 2016;52 (2):186-94.

How to Cite this article: Dimple Antiya, Suvarna Ganvir. Electromyographic activity of various muscles during sit-tostand in patients with stroke: a meta-analysis. Int. j. clin. biomed. res. 2018;4(3): 14-20. 